\title{
AN OPERATOR INEQUALITY WHICH IMPLIES PARANORMALITY
}

\author{
ARIYADASA Aluthge AND DERMING WANG
}

Abstract. Let $T$ be a bounded linear operator on a Hilbert space. Among other things, it is shown that (1) if $\left|T^{2}\right| \geqslant|T|^{2}$, then $T$ is paranormal, (2) if $T$ is $w$-hyponormal, then $\left|T^{2}\right| \geqslant|T|^{2}$ and $\left|T^{*^{2}}\right| \leqslant\left|T^{*}\right|^{2}$, and (3) if $T$ and $T^{*}$ are $w$-hyponormal, and either $\operatorname{ker} T \subseteq \operatorname{ker} T^{*}$ or $\operatorname{ker} T^{*} \subseteq \operatorname{ker} T$, then $T$ is normal.

Mathematics subject classification (1991): 47B20, 47A63.

Key words and phrases: Hyponormal operator, p-hyponormal operator, log-hyponormal operator, $w$-hyponormal operator, paranormal operator.

\section{REFERENCES}

[1] A. AluthGE, On p-hyponormal operators for $0<p<1$, Integr. Equat. Oper. Th., 13 (1990), 307-315.

[2] A. AluthGE AND D. WANG, $w$-Hyponormal operators, to appear in Integr. Equat. Oper. Th.

[3] A. AluthGe AND D. WANG, Powers of p-hyponormal operators, to appear in J. Inequal. Appl.

[4] T. ANDO, Operators with a norm condition, Acta. Sci. Math., 33 (1972), 169-178.

[5] T. ANDO, On some operator inequality, Math. Ann., 279 (1987), 157-159.

6] M. FUJII AND E. KAMEI, Furuta's inequality for the chaotic order, Math. Japon., 36 (1991), 603-606.

[7] T. FuRUTA, On the class of paranormal operators, Proc. Japan Acad., 43 (1967), 594-598.

[8] P. R. Halmos, A Hilbert Space Problem Book, Van Nostrand, Princeton, New Jersey, 1967. 